\title{
PLANO DE PREVENÇÃO E COMBATE A INCÊNDIOS FLORESTAIS PARA O CAMPUS DA UNICENTRO/IRATI
}

\author{
Álvaro Boson de Castro Faria ${ }^{1}$, Paulo Costa de Oliveira Filho ${ }^{2}$, Attilio Antonio Disperati ${ }^{3}$, \\ Diego Luis Venâncio ${ }^{4}$, Paulo Cândido da Silva ${ }^{5}$ \\ ${ }^{1}$ Eng. Florestal, M.Sc., Depto. de Engenharia Florestal, UNICENTRO, Irati, PR, Brasil - alvaro.faria@ onda.com.br \\ ${ }^{2}$ Eng. Florestal, Dr., Depto. de Engenharia Ambiental, UNICENTRO, Irati, PR, Brasil - paulocostafh@ gmail.com \\ ${ }^{3}$ Eng. Florestal, Dr., Depto. de Engenharia Florestal, UNICENTRO, Irati, PR, Brasil - disperati@avalon.sul.com.br \\ ${ }^{4}$ Eng. Ambiental, Mestrando em Ciências Florestais, UNICENTRO, Irati, PR, Brasil - diegoluisvenancio@ yahoo.com \\ ${ }^{5}$ Técnico Florestal, UNICENTRO, Irati, PR, Brasil - paulocandido@irati.unicentro.br
}

Recebido para publicação: 10/06/2008 - Aceito para publicação: 11/03/2009

\begin{abstract}
Resumo
Em junho de 2007, um incêndio alcançou as imediações da Unicentro, colocando em risco benfeitorias, edificações, bem como funcionários e alunos ali presentes. Diante desse fato, este trabalho teve como objetivo geral desenvolver um plano de prevenção e combate a incêndios florestais para o Campus e, como objetivos específicos: a) determinar os pontos de maior grau de perigo na área de estudo; b) dimensionar a infraestrutura a partir dos recursos disponíveis; c) avaliar a eficiência do sistema de vigilância e monitoramento das ocorrências. A análise dos dados foi realizada em ambiente de sistema de informações geográficas (SIG), através do aplicativo Spring 4.4.3, e subsidiada com diversas publicações que descrevem as etapas da elaboração desse tipo de levantamento. Os resultados permitiram chegar às seguintes conclusões: os pontos de maior grau de perigo de incêndios no Campus estão localizados na entrada, nas áreas próximas às edificações e na região da pedreira; os recursos disponíveis permitiram a aquisição de uma infraestrutura com equipamentos básicos de controle a incêndios; o sistema de vigilância e monitoramento das ocorrências está parcialmente adequado para a área de estudo. Diversas atividades foram descritas para compor o plano de prevenção e combate a incêndios florestais do Campus Universitário de Irati da Unicentro.
\end{abstract}

Palavras-chave: Zoneamento de risco; gestão florestal; proteção florestal; geoprocessamento; SIG.

\begin{abstract}
Forest fire prevention and suppression plan for the Unicentro/Irati Campus. In June of 2007 a fire got close to the main buildings of the Unicentro Irati Campus, placing at risk buildings, constructions, as well as employees and academic students present at that time. Due to this fact, this work had as a general objective to develop a forest fire prevention and suppression plan for the Campus, and as secondary objectives: a) to determine the points of higher risk of forest fire in the study area; b) to evaluate the infrastructure based on the available resources; c) to evaluate the efficiency of the monitoring system. The analysis of the data was carried out through a remote sensing and GIS Spring 4.4.3 software, and subsidized with diverse publications that describe the steps of the elaboration of this type of activity. The results evidenced the following conclusions: the points of highest risks of forest fire in the Campus are located at the entrance, in the areas next to the constructions, and at the quarry region; the available financial sources allowed the acquisition of an infrastructure with basic equipment for fire control; the monitoring system is partially adequate for the study area. Several activities have been described to compose the forest fire control plan for the Unicentro Campus.

Keywords: Risk zoning; forest management; forest protection, geoprocessing; GIS.
\end{abstract}

\section{INTRODUÇÃO}

Entre os fatores que contribuem para a ocorrência de incêndios florestais descontrolados em áreas rurais, destacam-se o uso do fogo para renovação de pastos e limpeza de áreas desmatadas em fase de conversão para usos agrícolas (BATISTA; SOARES, 2003; BONFIM et al., 2003). A velocidade com 
que a combustão devolve ao meio atmosférico o carbono fixado pela fotossíntese das plantas e a perda de biodiversidade de áreas naturais fazem do estudo da prevenção e combate de incêndios florestais um importante instrumento de mitigação dos impactos da atividade humana sobre os ecossistemas.

O Campus Universitário de Irati, Universidade Estadual do Centro-Oeste (Unicentro), está localizado no meio rural de uma região caracterizada por invernos secos e rigorosos. Estudos como os de Batista et al. (2002) e Deppe et al. (2004) comprovaram que, nesses períodos, essa região apresenta o maior número de ocorrências de incêndios do estado, associados à alta concentração de materiais combustíveis secos pelas geadas de outono e inverno, que acometem a vegetação local. Em 18 de junho de 2007, um incêndio alcançou as imediações da referida universidade, colocando em risco benfeitorias, edificações, bem como funcionários e alunos ali presentes (fotos e detalhes em DISPERATI et al., 2008).

Batista (2000), Batista; Soares (2003) e MMA (2006) descrevem as atividades de zoneamento do risco, caracterizando cinco fatores que subsidiam a confecção dos mapas de risco: presença humana, tipo de cobertura vegetal, características do material combustível, topografia e condições climáticas.

Alguns estudos sobre a elaboração de planos de prevenção e controle de incêndios florestais em unidades de conservação, empresas e instituições de ensino (FERRAZ; VETTORAZZI, 1998; BONFIM et al., 2003; PARIZOTTO et al., 2004; MELO et al., 2004; VENTURI; ANTUNES, 2007; SANTANNA et al., 2007) estão disponíveis na literatura. Tais trabalhos descrevem ações, como o zoneamento do risco, a análise de estatísticas de ocorrências do local, o acompanhamento de índices de perigo, o dimensionamento da infraestrutura e o planejamento dos sistemas de vigilância, que auxiliam na tomada de decisão em relação à prevenção e combate a incêndios florestais.

Este trabalho teve como objetivo geral desenvolver um plano de prevenção e combate a incêndios florestais para o Campus. Os objetivos específicos foram: a) determinar os pontos de maior grau de perigo na área de estudo; b) dimensionar a infraestrutura a partir dos recursos financeiros disponíveis; c) avaliar a eficiência do sistema de vigilância e monitoramento das ocorrências.

\section{MATERIAL E MÉTODOS}

\section{Área de estudo}

A pesquisa foi realizada no ano de 2007, na área interna do Campus Universitário de Irati da Unicentro (70,00 ha) e nas áreas de seu entorno (96,00 ha), totalizando 166,00 ha.

O Campus está localizado no município de Irati, Paraná, no paralelo $25^{\circ} 27^{\prime} 56^{\prime \prime}$ de latitude sul, com interseção com o meridiano 50 $37^{\circ} 51^{\prime \prime}$ de longitude oeste e a $150 \mathrm{~km}$ de Curitiba. Encontra-se na região do Segundo Planalto Paranaense, com clima tipo $\mathrm{Cfb}$ segundo a classificação de Köppen, com geadas frequentes no inverno.

\section{Material}

Foram utilizados os seguintes materiais:

- Imagem orbital (colorido normal e resolução espacial de $61 \mathrm{~cm}$ ) do sensor Quickbird a bordo do satélite Quickbird II, do ano de 2004, cedidas pela Prefeitura Municipal de Irati, abrangendo a parte urbana de Irati e suas imediações.

- Mapa digital da área do Campus, cedido pela empresa Engefoto Ltda., contendo isolinhas altimétricas de metro em metro.

- Ambiente de Sistema de Informações Geográficas (SIG), mais precisamente o aplicativo Spring.

- Sistema de Processamento de Informações Georreferenciadas, versão 4.3.3 (SPRING, 1996).

- Fotos terrestres obtidas em campo.

\section{Métodos}

Para a elaboração dos mapas referentes ao Campus, foi executada a seguinte sequência de atividades pela equipe do Laboratório de Geoprocessamento do Departamento de Engenharia Florestal (DEF) da Unicentro, fundamentais na discussão deste trabalho:

- estruturação do modelo de dados em ambiente SIG, em diversos planos de informações;

- conversão da resolução radiométrica das imagens digitais orbitais, de onze bites para oito bites;

- correção geométrica das bandas de imagem, com uso do mapa digital, para aumentar a precisão e 
melhorar a sobreposição dos dados de altimetria com as bandas de imagem;

- realce das imagens e formação da imagem sintética em falsa cor (composição colorida);

- elaboração de um buffer de 200 metros de distância para a demarcação da área do entorno do Campus;

- criação da máscara e posterior recorte da imagem para a redução do tamanho dos arquivos matriciais, facilitando o processamento das imagens;

- trabalhos de segmentação, classificação e edição vetorial, para a elaboração do mapa de uso e ocupação do solo, tanto da área interna quanto externa ao Campus, na região do seu entorno, considerando o buffer de 200 metros de seus limites;

- procedimento de edição vetorial das isolinhas altimétricas;

- elaboração do modelo numérico do terreno para a altimetria (MNT altimétrico);

- elaboração do mapa de declividade;

- interpretação dos dados sob a perspectiva de prevenção a incêndios florestais.

Os mapas confeccionados caracterizaram os fatores de risco descritos por Batista (2000), Batista; Soares (2003), MMA (2006) e Santanna et al. (2007). Foram descritos o uso e a ocupação do solo, com as atividades produtivas desenvolvidas nas áreas confrontantes, destacando-se as edificações e tipos de pavimentação presentes (fatores antrópicos). Também foram localizados os corpos hídricos e descritos os tipos de cobertura vegetal (herbácea, arbustiva, arbórea) da área (fatores relacionados ao tipo de cobertura vegetal e ao material combustível). Em seguida, foram evidenciadas as características de declividade da área de estudo (fatores topográficos).

A partir dos dados de Batista et al. (2002) e Deppe et al. (2004), considerou-se que a época de maior risco de incêndios na região está compreendida entre os meses de maio a outubro (fatores climáticos).

Para facilitar a discussão do plano de prevenção e combate a incêndios florestais, as informações foram organizadas com base nas ações propostas por Ferraz; Vettorazzi (1998), Bonfim et al. (2003), Melo et al. (2004), Venturi; Antunes (2007) e Santanna et al. (2007) - mapas com os fatores de risco, estatísticas descritivas, índices de perigo, dimensionamento da infraestrutura e sistema de vigilância. $\mathrm{O}$ procedimento de coleta de dados estatísticos seguiu as recomendações de Larson; Farber (2004) para informações descritivas qualitativas e discretas, no qual as variáveis de estudo foram o dia de ocorrência de incêndio, o local de ocorrência e se houve auxílio do Corpo de Bombeiros para seu controle. Em seguida, foram tecidas considerações sobre o sistema de informações geográficas utilizado como ferramenta de apoio do presente trabalho.

\section{RESULTADOS E DISCUSSÃO}

\section{Mapas com os fatores de risco}

A determinação dos pontos de maior grau de perigo se iniciou pela análise das áreas de entorno do Campus, especificamente o tipo de cobertura vegetal, os corpos hídricos e as edificações (Figura 1), através da qual se constataram algumas áreas com agricultura (plantios de soja e milho), onde podem ser realizadas queimadas para limpeza do terreno, geralmente nos períodos de primavera e outono. Outras áreas apresentam vegetação herbácea rasteira altamente suscetível à ação das geadas de inverno, o que aumenta a disponibilidade de materiais combustíveis secos.

As divisas da região oeste e noroeste e as áreas internas do Campus apresentam estradas secundárias de pavimentação com cascalhos, que funcionam como aceiros de segurança. Evidencia-se a necessidade de limpeza frequente dos matos dessas estradas, que apresentam baixa trafegabilidade. Essa limpeza pode ser executada através de roçadas manuais ou semimecanizadas, com posterior remoção desses resíduos, nas épocas antecedentes ao inverno. Desse modo, será diminuída a continuidade dos materiais combustíveis no solo. Igualmente importante é salientar a necessidade de comunicação com os proprietários das áreas confrontantes, que podem avisar a equipe de funcionários do Campus sobre a realização das queimadas, evitando imprevistos e angariando auxílio em seu monitoramento (Figura 1).

A área de entorno apresenta localidades com corpos hídricos que podem ser utilizados como fontes de captação de água para abastecimento das equipes de combate. O primeiro a nordeste, localizado na entrada do Campus, consiste em um açude a montante do rio Riozinho, utilizado para abastecimento dos proprietários rurais da região e para a dessedentação de animais. Já no extremo oeste, nas imediações 
do Campus, há a formação de um lago, utilizado como recreação pela vizinhança. É possível constatar nesse ponto uma importante área de regeneração arbustiva, constituindo a faixa de preservação permanente desse fundo de vale.

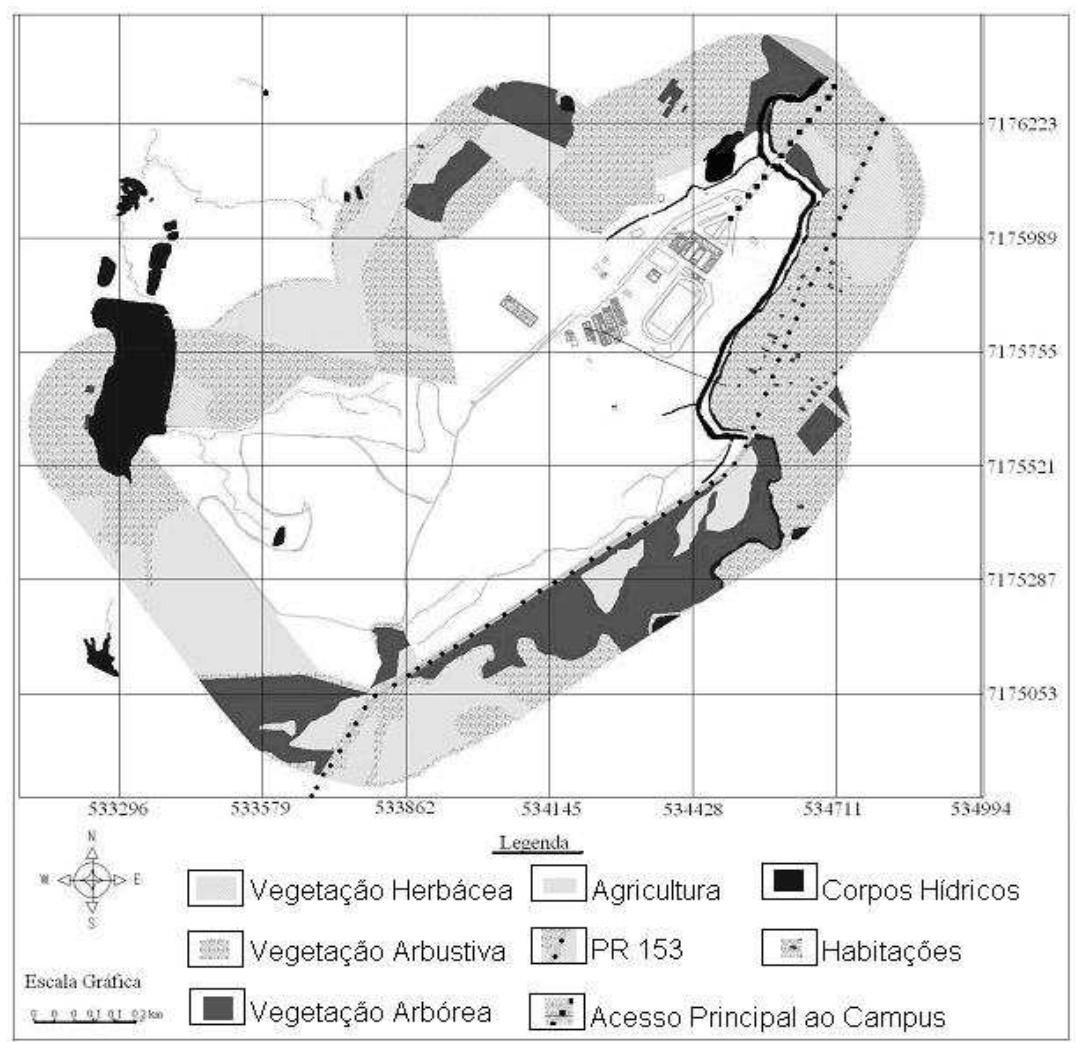

Figura 1. Área de entorno do Campus.

Figure 1. Area around the Campus.

Importa destacar que uma das divisas, parte sudeste do Campus, é caracterizada por vegetação arbórea (mata secundária) ciliar do rio Riozinho, importante para evitar seu assoreamento e para contribuir com a manutenção da biodiversidade local. Nessas áreas, infere-se que o risco é significativamente menor, em função da maior umidade presente no solo e na vegetação.

A área de entorno a leste do Campus, é transitada pela PR-153 (Figura 1), rodovia que interliga Irati a Rio Azul. A presença de vegetação rasteira na entrada do Campus, à margem da rodovia, juntamente com algumas habitações, caracteriza uma importante faixa de risco de incêndios, que precisa ser monitorada principalmente nos períodos de geadas. Nesse ponto, recomendam-se estratégias ativas de educação ambiental, para promover a conscientização dos moradores e evitar atividades de risco nas épocas secas.

Dando atenção à parte interna do Campus (Figura 2), verifica-se uma área com bastante vegetação arbórea (mata secundária) e uma área com vegetação arbustiva (capoeirinha), bem como outras com vegetação herbácea (matos). As áreas de maior risco são aquelas próximas às edificações, em função da alta movimentação de pedestres, muitos deles fumantes.

A PR-153 contorna o limite ao sul e sudeste do Campus e em sua extensão mais retilínea abrange uma longa faixa de vegetação rasteira, que se desenvolve em uma pedreira abandonada existente na área interna (Figura 2). Somente entre maio e junho de 2007 o tráfego de veículos motorizados e de pedestres nessas redondezas foi responsável por três ocorrências de incêndios, sendo que apenas uma foi controlada com auxílio do Corpo de Bombeiros, caracterizando essa região como uma das mais críticas no tocante às atividades de prevenção. É de suma importância a execução sistemática de limpeza do material combustível presente nas margens e a construção de uma cerca delimitando a divisa do Campus, que impeça a entrada de 
transeuntes nessas imediações. Para o planejamento de médio e longo prazos, um programa de recuperação de áreas degradadas poderia permitir ali o desenvolvimento acelerado de uma vegetação de porte arbóreo, permitindo a recomposição do horizonte superficial do solo e fornecendo umidade suficiente para diminuir significativamente o grau de perigo de incêndios. Essas árvores também poderiam funcionar como barreira quebra-vento, reduzindo a velocidade de propagação do fogo em eventuais ocorrências. Existe na pedreira um afloramento d'água, presente apenas em épocas chuvosas, mas que pode auxiliar as equipes de combate na captação de água em ocorrências de incêndios nesse local.

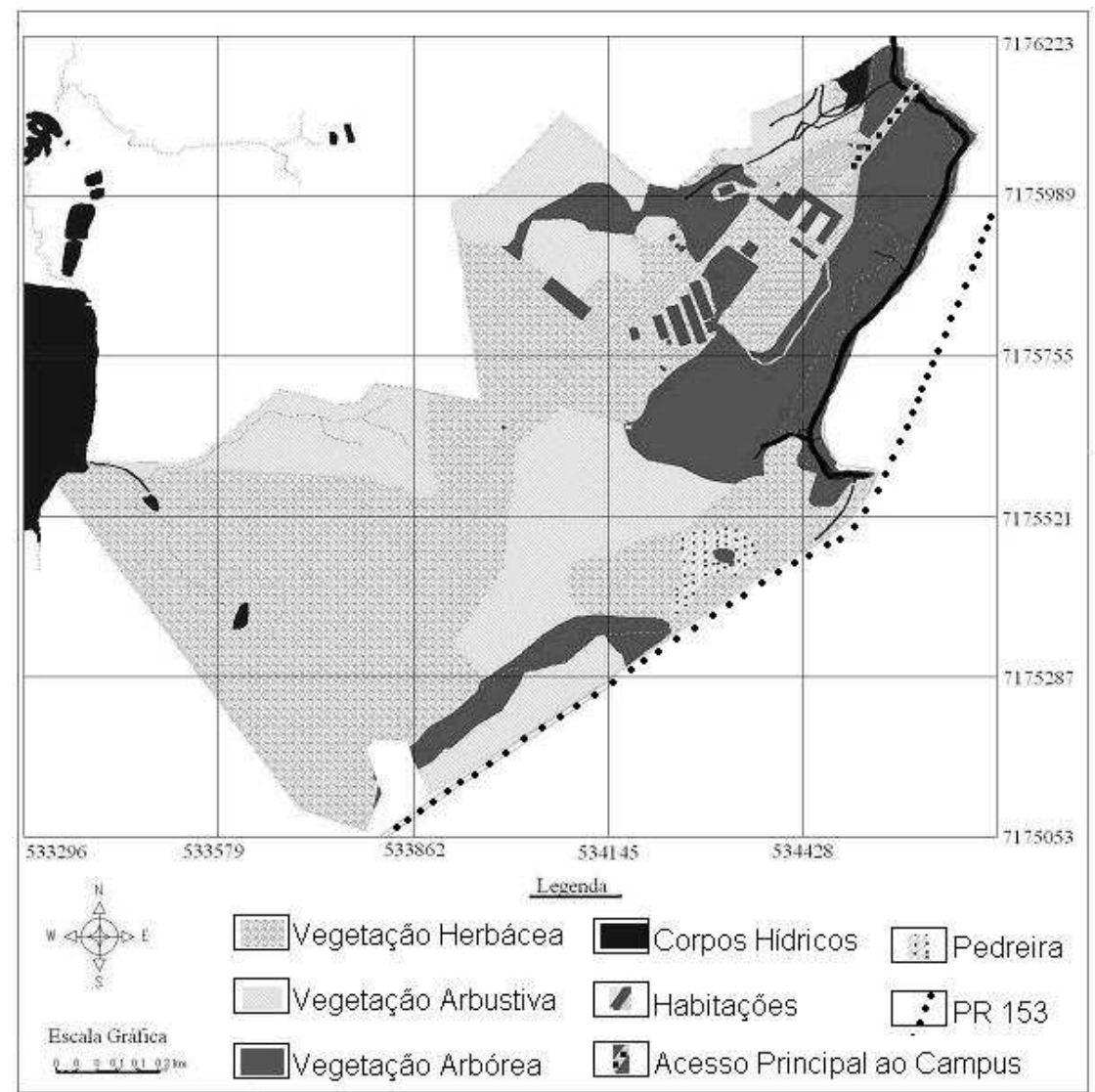

Figura 2. Atividades nas áreas internas do Campus.

Figure 2. Campus internal areas characteristics.

A partir do mapa com as características de declividade (Figura 3), foi possível inferir sobre a movimentação das correntes de vento locais, que direcionam a propagação dos incêndios florestais. Considerando o argumento de Ferraz e Vettorazzi (1998) de que a transferência de calor é facilitada no sentido do aclive, aumentando a velocidade de propagação, percebem-se duas situações na região com maior declividade, a sudeste da área de estudo. A primeira, com vegetações arbóreas (matas secundárias, Figura 2), devido à sua umidade natural, apresenta menor probabilidade de ocorrência de incêndios.

No entanto, a declividade acentuada na região da pedreira e a abundância de materiais combustíveis fizeram com que a ação conjunta entre a movimentação das correntes de vento e a ação antrópica (causadora da fonte inicial de calor, como, por exemplo, ponteiras de cigarros) tivessem sido responsáveis pela maioria das ocorrências registradas (Tabela 1), caracterizando uma área de grande risco de incêndios. Reitera-se a necessidade da construção de uma cerca impedindo o livre acesso dessas áreas aos pedestres da rodovia. 


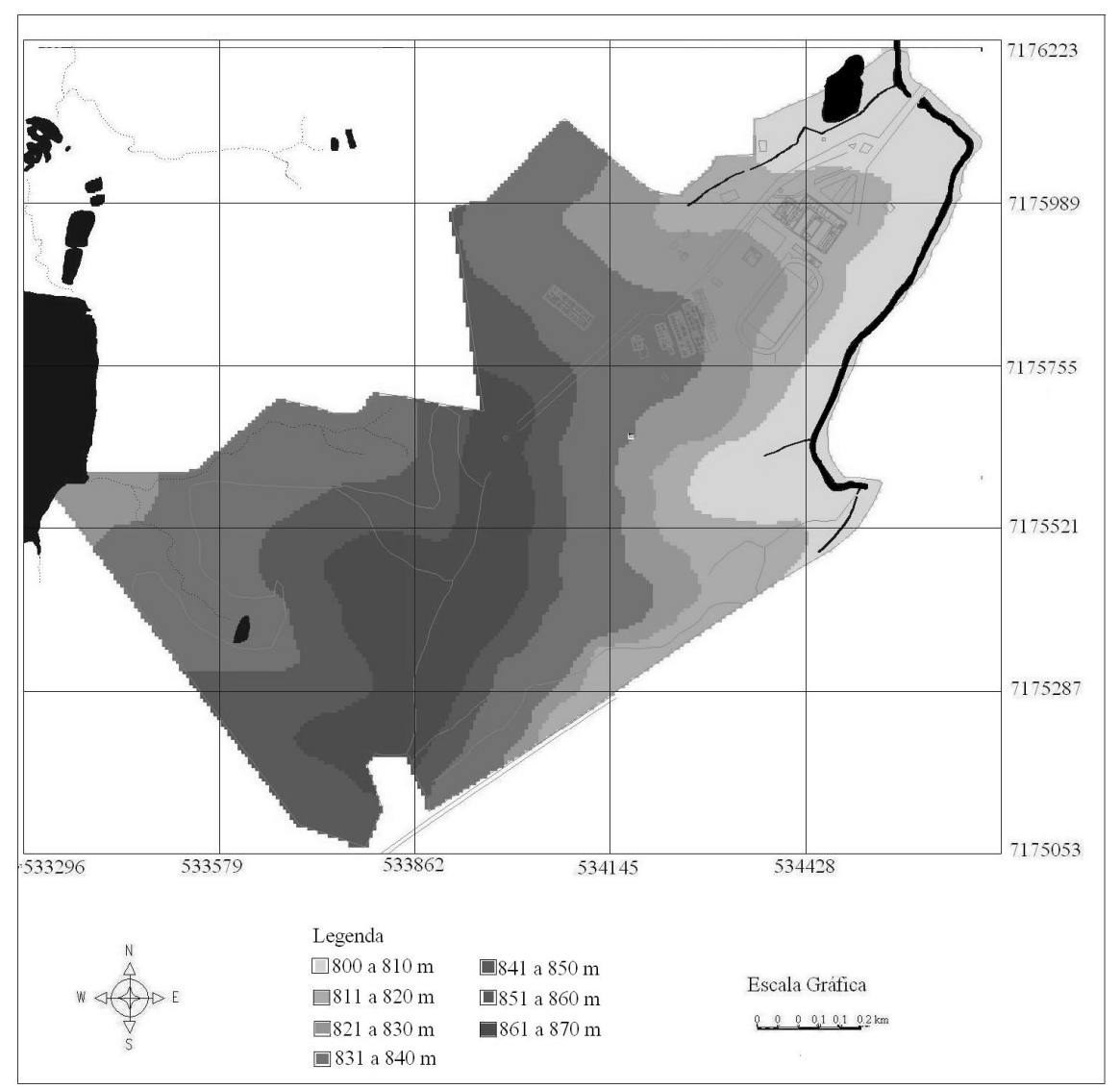

Figura 3. Características de declividade do Campus.

Figure 3. Digital terrain model of the Campus of Irati.

\section{Estatísticas descritivas}

Os dados se referem ao ano de 2007 e incluem as ocorrências que foram detectadas e controladas pelos contratados na manutenção externa do Campus, gerenciada pelo DEF. Tais ocorrências confirmam os pontos de maior grau de perigo detectados nos mapas, ou seja, a entrada do Campus, as áreas próximas às edificações e a área da pedreira (Tabela 1).

Tabela 1. Registro das ocorrências de incêndios no Campus em 2007.

Table 1. Forest fires occurrences in the Campus, in 2007.

\begin{tabular}{lccc}
\hline Data & Dia da semana & Local & $\begin{array}{c}\text { Presença do Corpo de } \\
\text { Bombeiros }\end{array}$ \\
\hline 27 mai & Domingo & Pedreira & Não \\
18 jun & Segunda & Imediações do prédio da administração & Sim \\
19 jun & Terça & Pedreira & Não \\
21 jun & Quinta & Entrada & Sim \\
24 jun & Domingo & Pedreira & Sim \\
\hline
\end{tabular}

Fonte: Os autores.

Por volta das $15 \mathrm{~h}$ do dia 18 de junho de 2007, servidores e alunos detectaram um incêndio próximo ao prédio de administração do Campus. Os funcionários da instituição iniciaram o combate dessa ocorrência. Sem equipamentos adequados, contavam apenas com mangueiras de jardinagem e galhos de árvores, utilizados como abafadores. Após algum tempo, chegou o caminhão do Corpo de Bombeiros e, com o trabalho conjunto, o fogo foi dominado. 
Os fatores que contribuíram para o início do incêndio florestal estavam relacionados ao "triângulo do fogo" (citado por SANTANNA et al., 2007): oxigênio (intenso vento), alta quantidade de material combustível inflamável (devido ao longo período de estiagem) e fonte inicial de calor, que pode ter sido promovida pela queima de pasto dos proprietários de terrenos vizinhos e se espalhado sem controle até atingir parte do Campus. Outra causa provável para o começo do incêndio pode estar relacionada à ação de incendiários, devido à alta movimentação de pessoas nesse local. Nesse sentido, Disperatti et al. (2008) mostraram diversas fotografias digitais avaliando os impactos específicos dessa ocorrência e sua restauração após um período de dois meses.

Os levantamentos de estatísticas básicas e descritivas das ocorrências estão entre as primeiras ações de prevenção de incêndios florestais. Os locais, os tipos e formas dos incêndios, os tipos de vegetação queimados, as datas, as horas de detecção, o tamanho das áreas queimadas, o tempo para localização do foco de incêndio, o tempo gasto no controle de uma ocorrência, o rendimento das atividades de combate e em relação aos equipamentos disponíveis são variáveis que precisam ser monitoradas para otimizar os recursos disponíveis. No Campus, tais informações devem ser coletadas por uma equipe de monitoramento, preparada para combater as próximas ocorrências de incêndios.

\section{Monitoramento dos índices de perigo}

Evidencia-se a necessidade de elaboração de estratégias de conscientização para diminuir o risco com os focos iniciais de calor. Como opção, sugere-se a instalação de uma placa indicando o grau de perigo de incêndio florestal diário na entrada do Campus.

No Brasil, o principal índice de risco de incêndios florestais é a fórmula de Monte Alegre (FMA), desenvolvida por Soares (1972) ${ }^{1}$. Trata-se de um índice cumulativo que leva em consideração apenas a umidade relativa do ar (13 hs), uma variável de fácil mensuração, e a precipitação pluviométrica, para a realização de cálculos de abatimento. O cálculo diário do FMA poderia ser realizado por funcionários do Campus, principalmente nas épocas de maior risco.

\section{Dimensionamento da infraestrutura para o controle de incêndios florestais}

Até o presente, o combate das ocorrências foi realizado com a equipe de seis funcionários terceirizados do setor de manutenção externa da universidade e dois acadêmicos voluntários do curso de engenharia florestal, sob comando do técnico florestal do DEF, com a utilização de galhos improvisados como abafadores manuais. Essa estrutura permitiu o controle dos incêndios, porém outras ocorrências puderam ser controladas apenas com o auxílio do Corpo de Bombeiros.

No ano de 2007, a administração do Campus adquiriu, através de licitação, alguns equipamentos de combate a incêndios (Tabela 2), que estão acondicionados no Laboratório de Proteção Florestal do DEF. Esses equipamentos estão à disposição para as aulas da disciplina de Incêndios Florestais, e se caracterizam como um importante avanço no sistema de combate das próximas ocorrências. Para tanto, faz-se importante o treinamento de uma brigada de incêndios composta por funcionários e voluntários.

Tabela 2. Equipamentos de combate a incêndios florestais acondicionados no Laboratório de Proteção Florestal/DEF.

Table 2. Forest fire supression equipments stored at the Forest Protection Laboratory.

\begin{tabular}{lc}
\hline Item & Unidades \\
\hline Abafadores & 10 \\
Queimador pinga-fogo & 1 \\
Caneleiras de couro & 10 pares \\
Luvas de couro & 10 pares \\
Capacetes & 10 \\
Máscaras de carvão ativado & 10 \\
Garrafas térmicas (5,0 litros) & 3 \\
\hline
\end{tabular}

Fonte: Os autores.

\footnotetext{
${ }^{1}$ SOARES, R.V. Determinação de um Índice de perigo de incêndio para a região centro-paranaense. Dissertação de mestrado. Turrialba, CATIE/IICA, 1972.
} 
Tendo em conta os equipamentos adquiridos e a demanda por novos equipamentos, torna-se imprescindível a aquisição de extintores costais, importantes para controlar as próximas ocorrências.

\section{Planejamento dos sistemas de vigilância}

O Campus da Unicentro dispõe de uma equipe terceirizada de dez vigias, que se revezam durante períodos diurnos e noturnos, monitorando a entrada e as edificações da universidade. Eles promovem a segurança interna das áreas e acompanham a ocorrência de incêndios. Esses funcionários não são responsáveis pelo combate propriamente dito, mas são atualmente a única alternativa para a detecção dos focos iniciais de calor.

Para os pontos de maior altitude da área de estudo (Figura 3), sugere-se a aquisição e instalação futura de uma torre de observação. Venturi e Antunes (2007) citam que o alcance visual ideal de uma torre é o de $15 \mathrm{~km}$, ou seja, sua instalação no Campus permitiria uma observação de aproximadamente $47,12 \mathrm{~km}^{2}$ (a área de uma circunferência de $15 \mathrm{~km}$ de raio), ou 4.712 ha, permitindo a observação e monitoramento de toda a área de influência do Campus (166 ha no total). A altura da torre deverá permitir que ela esteja sempre acima da altura máxima das áreas monitoradas. A torre poderá ter altura igual a 25 metros, conforme recomendações de Batista e Soares (2003) para instalação de torres em topos de morro, e será de extrema importância nas aulas práticas de incêndios florestais da graduação em engenharia florestal.

\section{CONCLUSÕES}

- Os pontos de maior grau de perigo de incêndios no Campus estão localizados na entrada, nas áreas próximas às edificações e na região da pedreira.

- Os recursos disponíveis permitiram a aquisição de uma infraestrutura com equipamentos básicos de controle a incêndios.

- O sistema de vigilância e monitoramento das ocorrências está parcialmente adequado para a área de estudo.

\section{REFERÊNCIAS}

BATISTA, A. C. Mapas de risco: uma alternativa para o planejamento de controle de incêndios florestais. Floresta, Curitiba, v. 30, n. 1/2, p. 45-54, 2000.

BATISTA, A. C.; OLIVEIRA, D. S.; SOARES, R. V. Zoneamento de risco de incêndios florestais para o estado do Paraná. FUPEF. Serie técnica, Curitiba, n. 2, 2002.

BATISTA, A. C.; SOARES, R. V. Manual de prevenção e combate a incêndios florestais. Curitiba: Fupef, 2003. $50 \mathrm{p}$.

BONFIM, V. R.; RIBEIRO, G. A.; SILVA, E.; BRAGA, G. M. Diagnóstico do uso do fogo no entorno do Parque Estadual da Serra do Brigadeiro (PESB), MG. Árvore, Viçosa, MG, v. 27, n. 1, 2003.

BRASIL. Ministério do Meio Ambiente (MMA). Roteiro metodológico para elaboração de planos operativos de prevenção e combate aos incêndios florestais em unidades de conservação. Brasília, DF, 2006.

CAMARA G.; SOUZA R.C. M.; FREITAS, U. M.; GARRIDO, J. SPRING: Integrating remote sensing and GIS by object-oriented data modelling. Computers \& Graphics, New York, v. 20, n. 3, p. 395-403, May-Jun 1996.

DISPERATI, A. A.; ALMEIDA, F. H.; OLIVEIRA FILHO, P. C.; FARIA, A. B. C. Registro fotográfico do incêndio florestal ocorrido na Unicentro - Campus universitário de Irati em junho de 2007. In: SEMINÁRIO DE PESQUISA, 19.; SEMANA DE INICIAÇÃO CIENTÍFICA DA UNICENTRO, 14., 2008, Curitiba: UNICENTRO, 2008.. 1 CD-ROM.

DEPPE, F.; MENEGHETTE, C. R.; VOSGERAU, J. Comparação de índice de risco de incêndio florestal com focos de calor no estado do Paraná. Floresta, Curitiba, v. 34, n. 2, p. 119-126, 2004. 
FERRAZ, S. F.; VETTORAZZI, C. A. Mapeamento de risco de incêndios florestais por meio de sistema de informações geográficas. Scientia Forestalis, Piracicaba, v. 53, p. 39-48, 1998.

MELO, D. D. V.; SILVEIRA, E. M. O.; DZEDZEJ, M.; PEREIRA, J. A. A. Diagnóstico rápido participativo no levantamento das causas de incêndios florestais no Campus da UFLA. Floresta, Curitiba, v. 34, n. 2, p 145-149, 2004.

LARSON, R.; FARBER, R. Estatística aplicada. 2. ed. São Paulo: Prentice Hall, 2004. 476 p.

PARIZOTTO, W.; SILVA, N. F.; TÉO, G. Capacitação para o combate e prevenção de incêndios florestais na região do Alto Irani, SC. Floresta. Curitiba, v. 34, n. 2, p. 113-118, 2004.

SANT'ANNA, C.M.; FIEDLER, N.C.; MINETTE, L.J. Controle de incêndios florestais. Alegre, ES. Os Editores, 2007. $152 \mathrm{p}$.

SOARES, R.V. Determinação de um Índice de perigo de incêndio para a região centro-paranaense. Dissertação (Mestrado) - Departamento de Ciencias Florestais/Centro Tropical de Ensino e Investigação Instituto de Investigação, Instituto Interamericano de Ciencias Agrícolas da OEA., Turrialba, 1972.

SOARES, R. V.; BATISTA, A. C. Meteorologia e climatologia florestal. Curitiba, Os Editores, 2004. $195 \mathrm{p}$.

VENTURI, N. L.; ANTUNES, A. F. B. Determinação de locais ótimos para implantação de torres de vigilância para detecção de incêndios florestais por meio de Sistema de Informações Geográficas. Floresta, Curitiba, v. 37, n. 2, p. 159-173, 2007. 